\title{
Comparing different versions of the Rahim El questionnaire in a South African context: A confirmatory factor analysis approach
}

\begin{abstract}
Authors:
Petrus Nel ${ }^{1}$

Marieta du Plessis ${ }^{2}$

Leon Bosman²

Affiliations:

${ }^{1}$ Department of Industrial Psychology, University of the Free State, South Africa

${ }^{2}$ Department of Industrial Psychology, University of the Western Cape, South Africa

Correspondence to: Petrus Nel

Email:

nelp1@ufs.ac.za

Postal address:

PO Box 339, Bloemfontein

9300 , South Africa

\section{Dates:}

Received: 14 May 2014 Accepted: 07 Nov. 2014

Published: 03 Mar. 2015

How to cite this article: Nel, P., Du Plessis, M., \& Bosman, L. (2015). Comparing different versions of the Rahim El questionnaire in a South African context: A confirmatory factor analysis approach. SA Journal of Industrial Psychology/SA Tydskrif vir Bedryfsielkunde, 41(1), Art. \#1220, 9 pages. http://dx.doi.org/10.4102/ sajip.v41i1.1220
\end{abstract}

\section{Copyright:}

(C) 2015. The Authors.

Licensee: AOSIS

OpenJournals. This work is

licensed under the Creative Commons Attribution

License.

\section{Read online:}

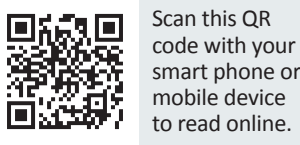

Orientation: Given the interest in the importance of emotional intelligence in employees and leaders with regard to performance of their jobs, it is imperative to use reliable and valid instruments to operationalise emotional intelligence.

Research purpose: The purpose of the study was to assess the psychometric properties of three different versions of the Rahim emotional intelligence index (EQI), specifically with regard to its factor structure and reliability, using two different samples.

Motivation for the study: No previous study has investigated which version of the Rahim EQI is the most appropriate for conducting research within South African organisations. In addition, the question of whether the Rahim EQI measures a strong general factor has not been answered.

Research approach, design, and method: A cross-sectional quantitative research design was used. Two samples were used $(n=470$ and $n=308)$. The first sample completed the 40 -item version of the Rahim EQI, whilst the second sample completed the 30-item version of the Rahim EQI. The measurement model, representing the 22-item version of the Rahim EQI, was also fitted to both these samples. Confirmatory factor analysis was used to compare the different versions, as well as conceptualisations, of the Rahim EQI.

Main findings: The 22-item version of the Rahim EQI exhibited better model fit than the 40-item and 30-item versions. In addition, the bifactor model suggested that the Rahim EQI seems to measure a strong general factor (emotional intelligence) with very little evidence of the presence of unique group factors (self-awareness, self-regulation, motivation, empathy and social skills).

Practical/managerial implications: Both the reliability and factor structure of the 22item version of the Rahim EQI have been confirmed. The bifactor structure should inform researchers and practitioners that, in order to understand emotional intelligence, it is better to conceptualise it as a unidimensional construct.

Contribution/value-add: In order to identify the most appropriate conceptualisation associated with the Rahim EQI, various goodness-of-fit statistics (e.g. comparative fit index and root mean square error of approximation) should be consulted. The impact of the removal of items from instruments should be investigated with regard to the accuracy with which the construct is to be measured. The current study has also contributed to the literature by examining the psychometric properties of the Rahim EQI in a South African sample.

\section{Introduction}

Although the existence and importance of intelligences beyond memory and problem solving (mostly defined as intelligence and tested by an IQ test) has long been recognised, it was not until relatively recently that serious efforts were made to define emotional intelligence (EI) (Goleman, 1995; Salovey \& Mayer, 1990). However, in the last two decades various research processes and efforts have been made to define and measure the impact of emotional intelligence on organisational outcomes (Cherniss, 2000; Cooper, \& Sawaf, 1997; Goleman, 1995, 1998; Mayer \& Salovey, 1997; Mayer, Salovey \& Caruso, 2000; Ryback, 1998; Weisinger, 1998).

In the process and scientific debate to propose an operational model of emotional intelligence, two markedly different, yet related, models of EI have been suggested (Ciarrochi, Chan \& Caputi, 2001). The first model is an 'ability model', which combines emotion with intelligence, and the second is what is termed a 'mixed model', which combines traits with social behaviours and competencies. The ability model has largely evolved from Salovey and Mayer's (1990) 
original definition of EI as a traditional intelligence and has attracted considerable research attention (Mayer \& Salovey, 1997; Salovey \& Mayer, 1990). Salovey and Mayer originally defined EI as the ability to deal with one's own emotions and those of others to benefit from problem solving and decisionmaking. The Mayer Salovey Caruso Emotional Intelligence Test (MSCEIT; Mayer, Salovey \& Caruso, 2002) is the most widely used ability measure of EI.

The mixed model (sometimes called the trait model), an approach generally embraced and advocated by Goleman (1995; 1998), arose largely from the work of Bar-On (1997). Bar-On (1997, p. 385) argues that emotional and social intelligence is a 'multifactorial array of interrelated emotional, personal, and social abilities that influence our overall ability to actively and effectively cope with daily demands and pressures'. The mixed model framework is generally comprised of self-report instruments that measure a combination of cognitive, personality and affective attributes (Papadogiannis, Logan \& Sitarenios, 2009). Examples of such instruments include the emotional quotient inventory (EQI; Bar-On, 1997), the Schutte self-report emotional intelligence test (Schutte et al., 1998) and the emotional competence inventory (Sala, 2002).

The last decade has seen a robust debate develop regarding the appropriateness and efficacy of the two models, a debate to which academic literature has greatly contributed (e.g. Emmerling \& Goleman, 2003). Advocates of the ability model argue that their models and measurement instruments are scientifically derived, and psychometrically independent, from other measures of personality (Mayer \& Salovey, 1997; Salovey \& Mayer, 1990). On the other hand, advocates of the mixed model argue that their approach is highly correlated with desired organisational outcomes, and is of significant value to organisational and leadership development (Emmerling \& Goleman, 2003; Goleman, 1995, 1998).

In addition to the debate surrounding the appropriateness of various models of emotional intelligence, a second debate has focused on the operationalisation (i.e. measurement) of the construct itself. Various authors have argued that it is better to use performance-based measures of emotional intelligence when it is conceptualised as an ability (Ashkanasy \& Daus, 2005; Joseph \& Newman, 2010; O'Boyle et al., 2011). In contrast, self-report measures of emotional intelligence, usually associated with the mixed model, seem to be contextualised for organisational research (Smollan \& Parry, 2011, p. 438). In addition, such measures are easier and faster when collecting data in comparison to measures of ability. More specifically, it has been found that ability-based measures of emotional intelligence seem to be more theoretically sound, yet suffer from poor predictive validity with regard to job performance. In contrast, mixed-model measures of emotional intelligence show strong relationships with job performance, but may suffer from questionable theoretical value (Joseph \& Newman, 2010, p. 71). The following quote summarises the current state of the debate: 'although EI is a wildly popular tool in organizations, organizational science has yet to answer many theoretical, measurement, and validity questions surrounding the construct' (Joseph \& Newman, 2010, p. 54).

\section{El measurements commonly used in South Africa}

As mentioned previously, the Rahim EQ index has not been used extensively in South African research. A review of the South African literature reveals a number of different EI measures currently being used for research purposes. The instruments used most often include the Schutte emotional intelligence scale (SEIS), the multi-dimensional emotional empathy scale, the assessing emotions scale (AES), the $360^{\circ}$ emotional competency profiler (ECP) and the Bar-On EQI. This is not an exhaustive list of EI measures, but merely a representation of the instruments most frequently used. The most frequently used measures will be discussed in further detail in the following sections.

\section{The Schutte emotional intelligence scale}

The SEIS is a self-report measure developed to assess trait emotional intelligence (Schutte, Malouff \& Bhullar, 2009). This scale is also referred to as the assessing emotions scale, the emotional intelligence scale or the self-report emotional intelligence test. The dimensions of the measure include assessment of perception, understanding and expression, as well as the regulation and harnessing of one's own emotions and those of others (Schutte et al., 2009). The scale was originally developed based on the subcategories of the Salovey and Mayer original EI model (Petrides \& Furnham, 2000). The SEIS is comprised of 33 items; respondents rate the extent to which they agree or disagree with each statement on a five-point Likert scale. The alpha reliability coefficients obtained in international studies range from 0.70 to 0.85 (Jonker \& Vosloo, 2008). South African studies that have utilised the SEIS reported reliability coefficients ranging between 0.54 and 0.73 for sub-dimensions of the SEIS.

Across 28 international samples, the measure exhibited an average Cronbach's alpha of 0.87 and good internal consistency, convergent and divergent reliability was found (Schutte et al., 2009). However, it should be noted that the factor structure of the scale presented differently in various studies. Jonker and Vosloo (2008) extracted six factors, namely 'positive affect', 'emotion-others', 'happy emotions', 'emotions-own', 'non-verbal emotions' and 'emotional management'. In a sample of British universities, Petrides and Furnham (2000) identified four factors for the SEIS. Schutte et al. (2009) published their factor analysis findings and concluded that the SEIS and AES measure emotional intelligence, and should be seen as a unidimensional construct. As the SEIS / AES has been found to have structures with one (Schutte et al., 2009), three (Austin, Saklofske, Huang \& McKenney, 2004), four (Ciarrochi, Chan, Caputi, \& Roberts, 2001; Petrides \& Furnham, 2000; Saklofske, Austin, \& Minski, 2003) and six factors (Jonker \& Vosloo, 2008), no consistent valid and reliable factor structure has been confirmed, especially within the South African context (Bester, 2012). 


\section{The multi-dimensional emotional empathy scale}

The multi-dimensional emotional empathy scale, originally developed by Caruso and Mayer (1998), consists of 26 items. The measure has six dimensions, namely suffering (eight items), positive sharing (five items), responsive crying (three items), emotional attention (four items), emotional contagion (two items) and feel for others (four items) (Caruso \& Mayer, 1998). A self-report measurement method was used, in which respondents indicated their agreement or disagreement with the statements on a five-point Likert response scale. Caruso and Mayer reported a Cronbach's reliability coefficient of 0.86 . The reliability coefficients associated with these six dimensions ranged between 0.44 and 0.80. In a South African sample $(n=212)$ alpha coefficients for the six sub-dimensions ranged between 0.32 and 0.85 (Olckers, Buys \& Grobler, 2010). After conducting factor analysis, Olckers et al. (2010) contend that the measure does not demonstrate sufficient construct validity. Unfortunately no alternative measurement models associated with this instrument have been suggested or compared to this instrument. Thus, additional research should be done to confirm the applicability and validity of the measure.

\section{The $360^{\circ}$ emotional competency profiler}

The ECP is a multi-rater assessment aimed at measuring trait-based emotional intelligence in the work context (Wolmarans \& Martins, 2001). The 360-degree ECP requires self-rating from the respondent being assessed and evaluation of the respondent by at least three other individuals (Palmer, Jansen \& Coetzee, 2006). The measure consists of 46 items and subdivides emotional intelligence into seven competencies (Coetzee, 2005). These competency dimensions are change resilience (seven items), emotional literacy (six items), integration of head and heart (six items), interpersonal relations (nine items), self-management (six items), self-motivation (six items) and self-esteem or self-regard (six items) (Wolmarans \& Martins, 2001). The ECP uses two four-point Likert scales to measure current levels of emotional intelligence competence and the importance of these EI behaviours to the respondent (Palmer et al., 2006). Cronbach's alpha coefficients for the sub-dimensions range between 0.85 and 0.95 (Wolmarans \& Martins, 2001). The overall reliability was reported to be 0.98 . Acceptable reliability for the ECP subscales, ranging from 0.51 to 0.79 , was also found in a South African sample $(n=107)$. The reliability coefficient in the study for the total ECP was 0.92 (Coetzee, Martins, Basson \& Muller, 2006). No evidence of factor analysis was included in these publications.

\section{Other measures}

According to the EI Consortium (http:/ / www.eiconsortium. org), other EI measures available for research purposes include the emotional and social competence inventory (Sala, 2002), the Genos emotional competency inventory, the group emotional competency inventory, the Mayer-Salovey-Caruso EI test(MSCEIT), the trait emotional intelligence questionnaire (TEIQue), the work group emotional intelligence profile and
Wong's emotional intelligence scale. The brief emotional intelligence scale (BEIS-10; Davies, Lane, Devonport \& Scott, 2010), Dulewich \& Higgs's emotional intelligence questionnaire (DHEIQ; Dulewicz, Higgs \& Slaski, 2001) and the Swinburne University emotional intelligence test (SUEIT; Palmer \& Stough, 2002) were also used for research purposes. Jonker and Vosloo (2008) provide a summary of both ability and trait EI measures for further reference.

\section{Rahim EQ index}

The Rahim EQI was developed based on the dimensions of EI as proposed by Goleman (1995). These dimensions are:

Self-awareness - The ability to be aware of which emotions, moods and impulses one is experiencing and why. This is also indicative of an individual's awareness of the effects their feelings have on others.

Self-regulation - The ability to keep one's own emotions and impulses in check and to remain calm and composed in volatile situations, irrespective of one's emotions.

Motivation - The ability to remain focused on goals despite setbacks. It also indicates an individual who is able to 'operate from hope for success rather than a fear of failure'.

Empathy - A person's ability to understand the feelings conveyed through verbal and non-verbal messages, providing emotional support when needed, and to understand the connection between others' emotions and behaviour.

Social skills - The ability of an individual to handle problems without demeaning others who work with them. This also includes the ability to refrain from letting one's own negative feelings towards another individual inhibit collaboration and to handle conflict with tact and diplomacy. (Rahim et al., 2002, p. 305)

Rahim et al. (2002) state that change in one dimension of EI is likely to have an impact on change in another dimension of EI. For instance, in order to handle emotional processes and deal with them effectively, one needs to have self-awareness and self-regulation. Self-awareness is also a prerequisite for self-regulation, empathy and social skills (Lane, 2000). These examples are characteristics of trait emotional intelligence, which is concerned with cross-situational consistencies in behaviour (Petrides \& Furnham, 2000).

When comparing Rahim's EQI with other measures of emotional intelligence, it is apparent that one of the main differences between the measures is the theoretical background of the construct. Hence, some measures were built on Mayer and Salovey's definition of EI (e.g. MSCEIT), whilst others were conceptualised using Goleman's definition (e.g. Bar-On EQI, SEIS, Rahim EQI). Nonetheless, most of the EI measures used in South Africa are multidimensional mixed method models, including the core emotion-processing abilities conventionally ascribed to EI, as well as other components that are indicative of an individual's capability for adaptive, intelligent behaviour, which promotes personal success, happiness and general well-being (Wood, Parker \& Keefer, 2009). The latter is also the case for the Rahim EQI. 


\section{Research purpose and objectives}

Rahim et al. (2002) state that the intent of developing the EQI was to develop a psychometrically sound measure of emotional intelligence. This was done in order to overcome some of the limitations experienced by other researchers in the use of self-report measures of mixed model emotional intelligence. Although Rahim et al. (2002) report results of the EQI for a South African sample $(n=84)$, there are not many other published South African studies that have utilised the Rahim EQI. Research also refers to a number of different versions of the measure, namely a 22-item, 30-item and 40-item version (Rahim et al., 2002). Taking into account the difficulties experienced with self-report measures of EI (e.g. operationalisation and theoretical basis), it would be imperative to determine the psychometric properties of the Rahim EQI.

The research questions for this study can therefore be summarised as follows:

1. Which version of the Rahim EQI is a more valid operationalisation of the emotional intelligence construct, within a South African context?

2. Which factor structure associated with the Rahim EQI is a more valid representation of the emotional intelligence construct within a South African context?

The current study will be one of the first to answer the above questions within a South African sample of working adults.

\section{Research design \\ Research approach}

In order to execute the research, the current study employed a cross-sectional design with a survey data collection technique. More specifically, a non-probability sampling technique (convenience sampling) was employed to select the participants to complete the Rahim EQI.

\section{Research method}

\section{Research participants}

The current study collected data using two versions of the Rahim EQI (Rahim et al., 2002), from two different samples. For the 40-item version of the instrument, data was collected from 470 subjects. The majority of the sample was male (71\%). The average age of the participants was 37 years $(\mathrm{SD}=8.06)$. Participants came from three different industries (70 = agriculture, $103=$ medical and $297=$ mining $)$.

For the 30-item version of the instrument, data was collected from 308 subjects. The majority of the sample was male $(56 \%)$. The average age of the participants was 34 years ( $S D=10.51)$. Participants camefrom three differentenvironments (95 $=$ medical, $58=$ media and $155=$ public service $)$.

\section{Measuring instruments}

The rater version of the EQI (Rahim et al., 2002) requires respondents to provide their opinions about the way they perceive their supervisors in relation to five dimensions (self-awareness, self-regulation, motivation, empathy and social skills). There are three versions of the Rahim EQI, depending on the number of items: (1) 40 items, (2) 30 items and (3) 22 items. The last version can be viewed as a shorter version of the first two measures. Individuals responded to the items using a seven-point scale ranging from 1 (strongly agree) to 7 (strongly disagree). Cronbach's alphas range between 0.77 and 0.86 for each of the five subscales (Rahim et al., 2002, p. 315), which is indicative of good item reliability.

\section{Research procedure and ethical clearance}

After the researchers had presented the research project and proposal to the research committees of both the department and the faculty, permission for the project and ethical clearance was granted. Research participants were informed that they were under no obligation to participate in the study. They were also informed that their anonymity would be ensured due to the fact that they were not required to provide any identification information. Finally, the participants were ensured that no individual results would be reported in any publications. Only aggregated data related to the total group would be reported and discussed.

\section{Statistical analysis}

The current study used confirmatory factor analysis (CFA) to compare and evaluate the different versions of the Rahim EQI. All analysis was conducted using Mplus 7.11 (Muthén \& Muthén, 2012). The data were treated as continuous. Through analysis of the covariance matrix, the data were assessed for multivariate normality (Jackson, Gillaspy \& Purc-Stephenson, 2009). To determine whether the data was skewed, the scaling correction factor reported by Mplus was used. This value ranged between 1.3896 and 1.6268 for the various measurement models. Given that values greater than 1 indicate that distributions deviate from normality (Byrne, 2012), the data were deemed to be skewed, which required the use of the robust maximum likelihood method of estimation (Raykov \& Marcoulides, 2006).

Several fit indices were used, including the Satorra-Bentler Scaled chi-square, root mean square error of approximation (RMSEA), standardised root mean square residual (SRMR) and comparative fit index (CFI). Values close to 0.95 for CFI are considered indicative of good model fit. It is suggested that values close to 0.06 are indicative of acceptable fit for SRMR and RMSEA (Hu \& Bentler, 1999). In addition, Akaike's information criterion (AIC) as well as Bayes information criteria (BIC) can be used when comparing competing models, with smaller values indicating the better fitting model (Byrne, 2012).

\section{Results}

Table 1 present the goodness-of-fit statistics based on Sample $1(n=470)$ associated with the 40-item and 22-item versions of the Rahim EQI. 
TABLE 1: Goodness-of-fit statistics (Sample 1, $n=470$ ).

\begin{tabular}{lccc}
\hline Model & $\begin{array}{c}\text { One-factor solution } \\
\text { (40 items) }\end{array}$ & $\begin{array}{c}\text { Original structure } \\
\text { (40 items) }\end{array}$ & $\begin{array}{c}\text { Original structure } \\
\text { (22 items) }\end{array}$ \\
\hline S-B $\chi 2$ & 2529.330 & 2052.917 & 425.288 \\
$d f$ & 740 & 730 & 199 \\
RMSEA & 0.072 & 0.062 & 0.049 \\
& $(0.069 ; 0.075)$ & $(0.059 ; 0.065)$ & $(0.043 ; 0.056)$ \\
CFI & 0.829 & 0.873 & 0.954 \\
SRMR & 0.054 & 0.052 & 0.034 \\
AIC & 59599.168 & 58923.403 & 32576.313 \\
BIC & 60097.496 & 59463.258 & 32891.921 \\
\hline $\begin{array}{l}\text { Note: S-B } \chi 2, \text { Satorra-Bentler Scaled chi-square; } d f \text {, degrees of freedom; RMSEA, root } \\
\text { mean square error of approximation; SRMR, standardised root mean square residual; } \\
\text { CFI, comparative fit index; AIC, Akaike's information criterion, BIC, Bayes information } \\
\text { criterion. }\end{array}$
\end{tabular}

TABLE 2: Goodness-of-fit statistics (Sample 2, $n=308$ ).

\begin{tabular}{|c|c|c|c|c|}
\hline Model & $\begin{array}{c}\text { Original } \\
\text { structure } \\
\text { (30 items) }\end{array}$ & $\begin{array}{c}\text { Original } \\
\text { structure } \\
\text { (22 items) }\end{array}$ & $\begin{array}{l}\text { One-factor } \\
\text { solution } \\
\text { (22 items) }\end{array}$ & $\begin{array}{l}\text { Bifactor } \\
\text { structure } \\
\text { (22 items) }\end{array}$ \\
\hline$S-B \times 2$ & 919.303 & 385.990 & 597.152 & 449.270 \\
\hline$d f$ & 395 & 199 & 209 & 193 \\
\hline RMSEA & $\begin{array}{c}0.066 \\
(0.060 ; 0.071)\end{array}$ & $\begin{array}{c}0.055 \\
(0.047 ; 0.063)\end{array}$ & $\begin{array}{c}0.078 \\
(0.070 ; 0.085)\end{array}$ & $\begin{array}{c}0.066 \\
(0.058 ; 0.074)\end{array}$ \\
\hline $\mathrm{CFI}$ & 0.912 & 0.950 & 0.896 & 0.932 \\
\hline SRMR & 0.037 & 0.035 & 0.041 & 0.106 \\
\hline AIC & 28735.184 & 21352.077 & 21707.641 & 21441.449 \\
\hline $\mathrm{BIC}$ & 29108.194 & 21635.564 & 21953.828 & 21747.317 \\
\hline
\end{tabular}

From Table 1 it is evident that, when using the 22-item version of the Rahim EQI, the original five-factor structure fits the data best (especially when examining the values associated with the CFI, RMSEA, and SRMR). It is also clear that this model has the lowest value associated with AIC.

The goodness-of-fit statistics based on Sample $2(n=308)$ associated with the 30-item and 22-item versions of the Rahim EQI are reported in Table 2.

On the basis of the information reported in Table 2, it appears the original five-factor structure fits the data best (especially when examining the values associated with the AIC, CFI, RMSEA, and SRMR) when using the 22-item version of the Rahim EQI. It is also clear that the bifactor model has acceptable fit. This may suggest that the Rahim EQI has a strong general factor (emotional intelligence), with five group factors (self-awareness, self-regulation, motivation, empathy and social skills).

Given the fact that the original structure of the Rahim EQI, using the 22-item version, provided the best fit to the data, the intercorrelations amongst the five dimensions (of this version of the questionnaire) are reported in Table 3.

From Table 3 it is clear that all the dimensions have high correlations (strong relationships). These high correlations may also lend support to the possibility that the Rahim EQI only measures a strong general factor. Additional support for this will be provided in Table 7 .
TABLE 3: Phi coefficient matrix (Sample 2, $n=308$ ).

\begin{tabular}{lccccc}
\hline Variable & $\mathbf{1}$ & $\mathbf{2}$ & $\mathbf{3}$ & $\mathbf{4}$ & $\mathbf{5}$ \\
\hline Self-awareness & 1 & - & - & - & - \\
Self-regulation & 0.905 & 1 & - & - & - \\
Motivation & 0.896 & 0.847 & 1 & - & - \\
Empathy & 0.960 & 0.866 & 0.908 & 1 & - \\
Social skills & 0.933 & 0.973 & 0.916 & 0.917 & 1 \\
\hline
\end{tabular}

TABLE 4: Reliability estimates (Sample 1, $n=470$ ).

\begin{tabular}{lcclccc}
\hline Variable & \multicolumn{2}{c}{ 40-item version } & & \multicolumn{2}{c}{ 22-item version } \\
\cline { 2 - 3 } \cline { 5 - 6 } & $\begin{array}{c}\text { Number of } \\
\text { Items }\end{array}$ & Alpha & & $\begin{array}{c}\text { Number of } \\
\text { Items }\end{array}$ & Alpha \\
\hline Self-awareness & 8 & 0.908 & & 4 & 0.877 \\
Self-regulation & 8 & 0.914 & & 5 & 0.894 \\
Motivation & 8 & 0.928 & & 5 & 0.888 \\
Empathy & 8 & 0.921 & & 4 & 0.854 \\
Social skills & 8 & 0.904 & & 4 & 0.844 \\
\hline
\end{tabular}

TABLE 5: Reliability estimates (Sample 2, $n=308$ ).

\begin{tabular}{lcccccc}
\hline Variable & \multicolumn{2}{c}{ 30-item version } & & \multicolumn{2}{c}{ 22-item version } \\
\cline { 2 - 3 } \cline { 6 - 6 } & $\begin{array}{c}\text { Number of } \\
\text { Items }\end{array}$ & Alpha & & $\begin{array}{c}\text { Number of } \\
\text { Items }\end{array}$ & Alpha \\
Self-awareness & 6 & 0.936 & & 4 & 0.910 \\
Self-regulation & 6 & 0.949 & & 5 & 0.939 \\
Motivation & 6 & 0.936 & & 5 & 0.918 \\
Empathy & 6 & 0.931 & & 4 & 0.901 \\
Social skills & 6 & 0.922 & & 4 & 0.897 \\
\hline
\end{tabular}

The reliability estimates for each of the three versions of the Rahim EQI are presented in Table 4 and Table 5.

On the basis of the results reported in Table 4 and Table 5 , it is evident that the five dimensions measured by the Rahim EQI have acceptable reliabilities, all exceeding 0.80 . It should be noted that the reliabilities obtained from Sample 2 $(n=308)$ are slightly higher than those obtained from Sample $1(n=470)$.

Table 6 provides the standardised loadings and standard errors associated with the 22-item version of the Rahim EQI.

It is clear that all the items have significant loadings on their respective dimensions.

Table 7 provides the standardised loadings of the bifactor model associated with the 22-item version of the Rahim EQI.

From Table 7 it is evident that all of items have higher loadings on the general factor than on the group factors (i.e. dimensions of the Rahim EQI). This is indicative of a strong general factor (Reise, Moore \& Haviland, 2010). Cronbach's alpha may be misleading when used to interpret how well a measure reflects a single construct, should multidimensionality be assumed (Cortina, as cited by Reise et al., 2010, p. 555). However, the omega hierarchical coefficient is a statistic that is based on a bifactor model representation (Reise et al., 2010). The omega hierarchical coefficient was 0.90 . 
TABLE 6: Standardised solution (Sample 2, $n=308$ ).

\begin{tabular}{|c|c|c|c|c|c|c|}
\hline Item & Self-awareness & Self-regulation & Motivation & Empathy & Social skills & Standard errors \\
\hline 3 & 0.847 & - & - & - & - & 0.026 \\
\hline 5 & 0.837 & - & - & - & - & 0.031 \\
\hline 8 & 0.844 & - & - & - & - & 0.029 \\
\hline 30 & 0.854 & - & - & - & - & 0.026 \\
\hline 1 & - & 0.850 & - & - & - & 0.023 \\
\hline 10 & - & 0.874 & - & - & - & 0.022 \\
\hline 13 & - & 0.895 & - & - & - & 0.023 \\
\hline 26 & - & 0.848 & - & - & - & 0.023 \\
\hline 2 & - & - & 0.760 & - & - & 0.036 \\
\hline 12 & - & - & 0.827 & - & - & 0.027 \\
\hline 19 & - & - & 0.878 & - & - & 0.025 \\
\hline 21 & - & - & 0.904 & - & - & 0.022 \\
\hline 23 & - & - & 0.802 & - & - & 0.033 \\
\hline 14 & - & - & - & 0.833 & - & 0.028 \\
\hline 25 & - & - & - & 0.899 & - & 0.017 \\
\hline 28 & - & - & - & 0.799 & - & 0.028 \\
\hline 6 & - & - & - & - & 0.755 & 0.042 \\
\hline 7 & - & - & - & - & 0.861 & 0.025 \\
\hline 16 & - & - & - & - & 0.845 & 0.030 \\
\hline 17 & - & - & - & - & 0.852 & 0.027 \\
\hline
\end{tabular}

TABLE 7: Bifactor model - Standardised solution (Sample 2, $n=308$ ).

\begin{tabular}{|c|c|c|c|c|c|c|}
\hline Item & General & Self-awareness & Self-regulation & Motivation & Empathy & Social skills \\
\hline 3 & 0.589 & 0.589 & - & - & - & - \\
\hline 5 & 0.662 & 0.575 & - & - & - & - \\
\hline 8 & 0.700 & 0.475 & - & - & - & - \\
\hline 30 & 0.848 & 0.002 & - & - & - & - \\
\hline 1 & 0.693 & - & 0.528 & - & - & - \\
\hline 10 & 0.788 & - & 0.334 & - & - & - \\
\hline 13 & 0.807 & - & 0.340 & - & - & - \\
\hline 26 & 0.822 & - & 0.163 & - & - & - \\
\hline 2 & 0.611 & - & - & 0.504 & - & - \\
\hline 12 & 0.729 & - & - & 0.367 & - & - \\
\hline 19 & 0.793 & - & - & 0.325 & - & - \\
\hline 21 & 0.796 & - & - & 0.421 & - & - \\
\hline 23 & 0.718 & - & - & 0.296 & - & - \\
\hline 14 & 0.764 & - & - & - & 0.245 & - \\
\hline 25 & 0.835 & - & - & - & 0.267 & - \\
\hline 28 & 0.803 & - & - & - & -0.093 & - \\
\hline 6 & 0.683 & - & - & - & - & 0.516 \\
\hline 7 & 0.805 & - & - & - & - & 0.163 \\
\hline 16 & 0.806 & - & - & - & - & 0.091 \\
\hline 17 & 0.827 & - & - & - & - & 0.112 \\
\hline
\end{tabular}

\section{Discussion}

When comparing the goodness-of-fit statistics associated with each of the three versions (22-item, 30-item and 40-item) of the Rahim EQI, the following conclusions can be drawn.

The only measurement model that pointed to acceptable levels of fit was the 22-item version of the Rahim EQI. When looking at the goodness-of-fit statistics of the current measurement model, it outperformed both the 30-item and 40-item versions of the Rahim EQI. The results obtained in this study were also better than those reported by Rahim et al. (2002). The measurement model associated with the 22 items produced a poor-fitting model in the South African sample $(n=84)$. The reliabilities associated with the five dimensions, in both samples $(n=470$ and $n=308)$, were acceptable, ranging between 0.84 and 0.94 . These reliabilities were better than those reported for the South African sample (Rahim et al., 2002). Given the findings of the current study, it seems that the 22-item version of the Rahim EQI represents the most 
parsimonious operationalisation of the construct requiring fewer parameters to be estimated resulting in a less complex measurement model. With fewer variables, such models have the potential for better fit (Hair et al., 2006, p. 826). Hence, it can be concluded that the 22-item version of the Rahim EQI has acceptable psychometric properties.

Both the 30-item and 40-item versions of the Rahim EQI produced acceptable levels of fit when taking into consideration both the RMSEA (0.066 and 0.062) and SRMR (0.037 and 0.052). In contrast, the CFI (0.912 and 0.873 ) indicated poor fit. The reliabilities associated with the five dimensions in both samples ( $n=470$ and $n=308$ ) all exceeded 0.90. In a study conducted by Schlechter (2005), the psychometric properties of the 40-item version of the Rahim EQI were evaluated. Schlechter (2005, p. 197) reported very high reliabilities associated with each of the five dimensions: self-awareness $(\alpha=0.92)$, self-regulation ( $\alpha=0.95)$, motivation $(\alpha=0.84)$, empathy $(\alpha=0.93)$ and social skills $(\alpha=0.91)$. It is clear that these results are comparable to the reliabilities reported in the current study. In addition, the goodness-of-fit statistics associated with the original five-factor structure are comparable to those obtained in the current study. Specifically, the current study found slightly better fit with regard to both the RMSEA $(0.062$ versus 0.1085$)$ and the SRMR (0.052 versus 0.069$)$, than that reported by Schlechter (2005, p. 199). In contrast, the latter study reported better fit when considering CFI ( 0.9678 versus 0.873). The current study concurs with Schlechter's (2005, pp. 200-201) conclusion that the original five-dimensional structure, using the 40-item version of the Rahim EQI, fitted the data poorly. Although the 30-item version of the Rahim EQI exhibited better fit than the 40 -item version, there is still room for improvement.

When comparing the psychometric properties of the Rahim EQI (22 items) with other similar instruments, the results are encouraging. Schutte et al. (1998) claim that their instrument measures a general EI factor. Petrides and Furnham (2000) criticise this assumption and continued to fit a unidimensional model. The latter model did not fit their data well $(\mathrm{RMSEA}=0.105, \mathrm{GFI}=0.69, \mathrm{CFI}=0.51)$. They continued with exploratory factor analysis that suggested a fourdimensional model. Unfortunately, Petrides and Furnham did not provide any fit statistics. In a South African sample, Jonker and Vosloo (2008) reported a four-dimensional structure associated with the instrument developed by Schutte et al. (1998). However, no fit statistics were calculated for the observed measurement model.

\section{Should a total score or five separate subscales be used?}

In contrast to the study by Petrides and Furnham (2000), the current study suggests that the EQI of Rahim consists of a strong general EI factor. This is based on the goodness-offit statistics associated with the bifactor model evaluated by the current study, as well as the standardised factor loadings reported in Table 7 . It is important to note that the values associated with AIC and BIC were just slightly higher than that produced by the original five-factor structure (22-item version). Meaningful interpretation of the five subscales requires that they yield different information. However, the five-factor model yields such strong factor relationships that it does not make much sense to treat those factors separately. Hence, it is suggested that researchers should rather calculate and use a total score for emotional intelligence, instead of calculating and using scores for each if the five subscales, when using the 22-item version of the Rahim EQI in future research. These findings are supported by Schutte et al. (1998, 2009), who suggest that emotional intelligence can be treated as a unidimensional construct.

\section{Practical implications}

More emotionally intelligent employees yield higher work performance (O’Boyle, Humphrey, Pollack, Hawver \& Story, 2011), as well as other desired workplace outcomes such as work engagement and flourishing (Schutte \& Loi, 2014). Various studies have indicated that emotional intelligence can be increased through training (Schutte \& Maouff, 2013). The Rahim EQI can therefore be used as a pre-measure and post measure to the EI training intervention, in order to determine to what extent the training had an impact on individuals' levels of self-perceived EI.

\section{Limitations and recommendations}

The current study agrees with Rahim et al. (2002, p. 317) that 'it is evident that continued research is necessary to improve the EQI'. Although the current study provides some insight into the structure of the Rahim EQI, there are some suggestions to improve future investigations.

The current study used data collected from two samples that were from different industries, with Sample 1 (excluding medical) requiring physical attributes to be honed and Sample 2 (excluding medical) requiring social attributes to be honed. Also, the managerial levels within the organisations were not considered in the measurement. Both these sampling issues might have had an influence on the results. Samples that are statistically similar in terms of the attributes mentioned (e.g. managerial levels and industry) are advised for future researchers when planning similar investigations.

It is also advisable to investigate the factorial invariance of the Rahim EQI in different South African sub-samples. This will enable researchers to determine whether culture plays a role in emotional intelligence. Finally, there are more advanced statistical techniques, such as Rasch analysis, that should be used to supplement the results obtained in the current study. Rasch analysis is the preferred analysis technique to investigate unidimensionality of a measuring instrument (Bond \& Fox, 2007). More specifically, 'the unidimensionality assumption states that the observations on the manifest variables (e.g. the items) are solely a function of a single continuous latent person variable' (De Ayala, 2009, p. 20). The Rasch model will allow researchers to identify those items that can be used 
to measure an individual's standing on the latent variable (emotional intelligence). Those items that may lead to misfit can be removed to improve the accuracy of the Rahim EQI as a measure of emotional intelligence. Therefore, the unidimensionality assumption should be tested using the Rasch model in order to investigate the validity of the suggestion that emotional intelligence can be treated as a unidimensional construct.

\section{Conclusions}

The psychometric properties of the 22-item version of the Rahim EQI seem to be acceptable. The original five-factor structure of the emotional intelligence construct fitted the data well, as evidenced by the overall goodness-of-fit statistics. The reliabilities associated with all the five dimensions (self-awareness, self-regulation, motivation, empathy and social skills) were high. However, the results obtained from the bifactor model cast doubt about the usefulness of these subscales. The bifactor model suggested that there was a strong general factor and that the five subscales added very little understanding to the construct over and above the general factor. Researchers should therefore be cautious when using these subscales, as the overlap amongst them is so large that treating them as unique and separate dimensions may be overly optimistic.

\section{Acknowledgements Competing interests}

The authors declare that they have no financial or personal relationship(s) that may have inappropriately influenced them in writing this article.

\section{Authors' contributions}

P.N. (University of the Free State), M.d.P. (University of the Western Cape) and L.B. (University of the Western Cape) collected the data and contributed to the conceptualisation and writing of the article. P.N. conducted the data analysis.

\section{References}

Ashkanasy, N.M., \& Daus, C.S. (2005). Rumours of the death of emotional intelligence in organizational behaviour are vastly exaggerated. Journal of Organizational Behavior, 26(4), 441-452. http://dx.doi.org/10.1002/job.320

Austin, E.J., Saklofske, D.H., Huang, S.H.S., \& McKenney, D. (2004). Measurement of emotional intelligence: Testing and cross-validating a modified version of Schutte et al.'s (1998) measure. Personality and Individual Differences, 36, 555-562. http://dx.doi.org/10.1016/S0191-8869(03)00114-4

Bar-On, R. (1997). The emotional intelligence inventory (EQ-I): Technical manual. Toronto, Canada: Multi-Health Systems.

Bester, S.M. (2012). Confirming the factor structure of the 41-item version of the Schutte emotional intelligence scale. Unpublished master's thesis, Department of Industrial Psychology, North-West University, South Africa.

Bond, T.G., \& Fox, C.M. (2007). Applying the Rasch model: Fundamental measurement in the human sciences. (2nd edn.). Mahwah, NJ: Lawrence Erlbaum \& Associates.

Byrne, B.M. (2012). Structural equation modelling with Mplus: Basic concepts, applications and programming. New York, NY: Routledge.

Caruso, D.R., \& Mayer, J.D. (1998). A measure of emotional empathy for adolescents and adults. Unpublished manuscript, University of New Hampshire, Durnham, UK.

Cherniss, C. (2000, April). Emotional intelligence: what is it and why it matters. Paper presented at the Annual Meeting of the Society for Industrial and Organizational Psychology, New Orleans, LA.

Ciarrochi, J.V., Chan, A.Y.C., \& Caputi, P. (2001). A critical evaluation of the emotional intelligence construct. Personality and Individual Differences, 28(3), 539-561. $\mathrm{http}: / / d x$. doi.org/10.1016/S0191-8869(99)00119-1
Ciarrochi, J., Chan, A., Caputi, P., \& Roberts, R. (2001). Measuring emotional intelligence. In J. Ciarocchi, J.P. Forgas, \& J.D. Mayer (Eds), Emotional intelligence in everyday life: A scientific inquiry (pp. 25-45). Philadelphia, PA: intelligence in ever
Taylor \& Francis.

Coetzee, M. (2005). The relationship beween personality preferences, self-esteem and emotional competence. Unpublished doctoral dissertation, Department of Industrial and Organisational Psychology, University of South Africa.

Coetzee, M., Martins, N., Basson, J.S., \& Muller, H. (2006). The relationship between personality preferences, self-esteem and emotional competence. SA Journal of Industrial Psychology, 32(2), 64-73. http://dx.doi.org/10.4102/ sajip.v32i2.233

Cooper, R.K., \& Sawaf, A. (1997). Executive EQ: Emotional intelligence in leadership and organisations. New York, NY: Grosset/Putnum.

Davies, K.A., Lane, A.M., Devonport, T.J., \& Scott, J.A. (2010). Validity and reliability of a brief emotional intelligence scale (BEIS-10). Journal of Individual Differences, 31(4), 198-208. http://dx.doi.org/10.1027/1614-0001/a000028

De Ayala, R.J. (2009). The theory and practice of item response theory. New York, NY: The Guilford Press.

Dulewicz, V., \& Higgs, M., \& Slaski, M. (2001). El general and general 360 user guide. Windsor, UK: NFER-Nelson.

Emmerling, R., \& Goleman, D. (2003). Emotional intelligence: Issues and common misunderstandings. Issues in Emotional Intelligence, 1(1), 1-32.

Goleman, D. (1995). Emotional intelligence: Why it can matter more than IQ. New York, NY: Bantam.

Goleman, D. (1998). Working with emotional intelligence. London, UK: Bloomsbury.

Hu, L., \& Bentler, P.M. (1999). Cutoff criteria for fit indexes in covariance structure analysis: Conventional criteria versus new alternatives. Structural Equation Modeling, 6, 1-55. http://dx.doi.org/10.1080/10705519909540118

Jackson, D.L., Gillaspy, J.A., \& Purc-Stephenson, R. (2009). Reporting practices in confirmatory factor analysis: An overview and some recommendations. Psychological Methods, 14, 6-23. http://dx.doi.org/10.1037/a0014694

Jonker, C.S., \& Vosloo, C. (2008). The psychometric properties of the Schutte emotional intelligence scale. South African Journal of Industrial Psychology, 34(2), 21-30.

Joseph, D.L., \& Newman, D.A. (2010). Emotional intelligence: An integrative metaanalysis and cascading model. Journal of Applied Psychology, 95, 54-78. $\mathrm{http} / / / \mathrm{dx}$.doi.org/10.1037/a0017286

Lane, R.D. (2000). Levels of emotional awareness: Neurological, psychological, and social perspectives. In R. Bar-On, \& J.D.A. Parker (Eds.), The handbook of emotional intelligence: Theory, development, assessment, and application at home, school, and in the workplace (pp. 171-191). San-Francisco, CA: Jossey-Bass.

Mayer, J.D., \& Salovey, P. (1997). What is emotional intelligence? Implications for educators. In P. Salovey, \& D. Sluyter (Eds.), Emotional development and emotional intelligence: Educational implications (2nd edn., pp. 3-31). New York, NY: Basic Books. http://dx.doi.org/10.1017/CBO9780511807947.019

Mayer, J.D., Salovey, P., \& Caruso, D.R. (2000). Competing models of emotional intelligence. In R. Stenberg (Ed.), Handbook of Human Intelligence (pp. 396-420). New York, NY: Cambridge University Press.

Mayer, J.D., Salovey, P., \& Caruso, D.R. (2002). Mayer-Salovey-Caruos emotional intelligence test (MSCEIT) User's Manual. Toronto, Canada: MHS Publishers.

Muthén, L.K., \& Muthén, B.O. (1998-2012). Mplus User's Guide. (7th edn.). Los Angeles, CA: Muthén \& Muthén.

O'Boyle, E.H., Humphrey, R.H., Pollack, J.M., Hawver, T.H., \& Story, P.A. (2011). The relation between emotional intelligence and job performance: A meta-analysis. Journal of Organizational Behavior, 32(5), 788-818. http://dx.doi.org/10.1002/job.714

Olckers, C., Buys, M.A., \& Grobler, S. (2010). Confirmatory factor analysis of the multidimensional emotional empathy scale in the South African context. SA Journal of Industrial Psychology, 36(1), 8 pages. http://dx.doi.org/10.4102/sajip. v36i1.856

Palmer, B., \& Stough, C. (2002). Swinburne University emotional intelligence test (workplace SUEIT). Interim technical manual (Version 2). Victoria, UK: Swinburne University of Technology.

Palmer, P.N., Jansen, C.A., \& Coetzee, M. (2006). Perceptions of South African managers' emotional intelligence: A preliminary investigation. Southern African Business Review, 10(1), 91-110.

Papadogiannis, P.K., Logan, D., \& Sitarenios, G. (2009). An ability model of emotional intelligence: A rationale, description, and application of the Mayer Salovey Caruos emotional intelligence test (MSCEIT). In C. Stough, D.H. Saklofske, \& J.D.A. Parker (Eds.) Assessing emotional intelligence: Theory, research, and applications (pp. 43-65). New York, NY: Springer Publishing. http://dx.doi.org/10.1007/9780-387-88370-0_3

Petrides, K.V., \& Furnham, A. (2000). On the dimensional structure of emotional intelligence. Personality and Individual Differences, 29(2), 313-320. http://dx.doi. org/10.1016/S0191-8869(99)00195-6

Rahim, M.A., Psenicka, C., Polychroniou, P., Zhao, J.-H., Yu, C.-S., Chan, K.A., et al. (2002). A model of emotional intelligence and conflict management strategies: A study in seven countries. International Journal of Organizational Analysis, 10(4) 302-326. http://dx.doi.org/10.1108/eb028955

Raykov, T., \& Marcoulides, G.A. (2006). A first course in structural equation modeling (2nd edn.). New Jersey: Lawrence Erlbaum Associates. http://dx.doi.org/10.1207/ s15328007sem1302_5

Reise, S.R., Moore, T.M., \& Haviland, M.G. (2010). Bifactor models and rotations: Exploring the extent to which multidimensional data yield univocal scores. Journa of Personality Assessment, 92(6), 544-559. http://dx.doi.org/10.1080/00223891. 2010.496477 
Ryback, D. (1998). Putting emotional intelligence to work: Successful leadership is more than IQ. Woburn, MA: Butterworth-Heinemann.

Saklofske, D.H., Austin, E.J., \& Minski, P.S. (2003). Factor structure and validity of a trait emotional intelligence measure. Personality and Individual Differences, 34, 707-721. http://dx.doi.org/10.1016/S0191-8869(02)00056-9

Sala, F. (2002). Emotional competence inventory (ECI): Technical manual. Boston, MA Hay/Mcber Group.

Salovey, P., \& Mayer, J.D. (1990). Emotional intelligence. Imagination, Cognition and Personality, 9, 185-211. http://dx.doi.org/10.2190/DUGG-P24E-52WK-6CDG

Schlechter, A.F. (2005). The influence of transformational leadership, emotional intelligence, trust, meaning and intention to quit on organisational citizenship behaviour. Unpublished doctoral dissertation, Department of Industria Psychology, Stellenbosch University, South Africa.

Schutte, N.S., \& Loi, N.M. (2014). Connections between emotional intelligence and workplace flourishing. Personality and Individual Differences, 66, 134-139. http://dx.doi.org/10.1016/j.paid.2014.03.031

Schutte, N.S., \& Malouff, J.M. (2013). Increasing emotional intelligence through training: Current status and future directions. International Journal of Emotional Education, 5, 56-72.
Schutte, N.S., Malouff, J.M., \& Bhullar, N. (2009). The assessing emotions scale. In C. Stough, D.H. Saklofske, \& J.D.A. Parker (Eds.), Assessing emotional intelligence: Stough, D.H. Saklofske, \& J.D.A. Parker (Eds.), Assessing emotional intelligence: Theory, research, and applications (pp. 119-134). New
Publishing. http://dx.doi.org/10.1007/978-0-387-88370-0_7

Schutte, N.S., Malouff, J.M., Hall, L.E., Haggerty, D.J., Cooper, J.T., Golden, C. et al. (1998). Development and validation of a measure of emotional intelligence. Personality and Individual Differences, 25(2), 167-177. http://dx.doi.org/10.1016/ S0191-8869(98)00001-4

Smollan, R., \& Parry, K. (2011). Follower perceptions of the emotional intelligence of change leaders: A qualitative study. Leadership, 7(4), 435-462. http://dx.doi org/10.1177/1742715011416890

Weisinger, H. (1998). Emotional Intelligence at Work. San Francisco, CA: Jossey-Bass.

Wolmarans, S., \& Martins, N. (2001). The 360 degree emotional competency profiler. Unpublished manual. Johannesburg, South Africa: Organisational Diagnostics and Learning Link International.

Wood, L.M., Parker, J.D.A., \& Keefer, K.V. (2009). Assessing emotional intelligence using the emotional quotient inventory (EQ-i) and related instruments. In C. Stough, D.H. Saklofske, \& J.D.A. Parker (Eds.), Assessing emotional intelligence: Theory, research, and applications (pp. 66-84). New York, NY: Springer Publishing. http://dx.doi.org/10.1007/978-0-387-88370-0_4 